\title{
Research on the Role of Text and Graphics in Brand Logo Design
}

\author{
Lizhu Liang ${ }^{1, *}$
}

\author{
${ }^{1}$ Neusoft Institute Guangdong, Foshan, Guangdong, China \\ *Corresponding author. Email: lianglizhu@nuit.edu.cn
}

\begin{abstract}
The brand logo is a visual symbol of the brand's core concept. Through in-depth research on the brand concept and brand service characteristics, the design direction can be accurately grasped. The key step in the design of the brand's logo is to first filter the keywords through mind maps, list the text formulas, and then convert the text formulas into graphic formulas. Because graphics can be ever-changing, turning graphics into design, which reflects the level of design creativity and ability, is the key to graphic logo design. If it is a pure text logo design, its text formula is displayed through the overall glyph structure, line thickness, body decoration and color. Its form of expression is more introverted, but it doesn't affect people's perception of the brand's connotation through the logo.
\end{abstract}

Keywords: brand, idea, text, graphics, formula, design

\section{INTRODUCTION}

Excellent logo design can establish a good image for the brand, satisfy consumers, and help brand development. The brand logo design is mainly divided into three forms: graphics, text, and the combination of graphics and text. Depending on the design content, the design methods are different. Taking Chinese characters as an example, the pictographic features of Chinese characters can be found in a clever combination of pictograms and graphics. Here, the author will analyze, research and summarize the methods and forms of logo design through design cases.

\section{THE BRAND NAME}

Brand names are as important as people's names. Good brand names make it easier to perceive the attributes and connotation of the brand and deepen the impression. On the contrary, it will be difficult to identify, affect the transmission of brand information, and delay product sales. It is easy for logo designers to ignore the importance of brand names for brand logo design. It is not feasible to treat brand names and logo designs separately. The birth of brand names before the brand logo is the highest expression of the brand's concept. With brand names, designers can quickly grasp the direction and tonality of the logo design. Although the brand name is not something that the designer can control, it is closely related to the logo design.

What makes a good brand name?
The following are some familiar brand names: Kelon, Galanz, Gree, Philips, Midea, Jiuyang, Boss, Fotile, Apple, Samsung, MIUI, Asus, Lenovo, Huawei, HP, Coca-Cola, Pepsi, Hedy, Sprite, Meilan Tak, Fanta, JDB, Ronghua, Wong Lo Kat, Yuanjilin, Sunkist, Red Bull, Pocari Sweat, Gatorade, Dove, Sands, Kinder, Snickers, Fuji, Kodak, Nike, Xtep, Li Ning, Septwolves, Oreo, Jiadun, Haitian, Weijixian, Master Kong, Cup Noodles, Demae Itcho, Liufu, Chow Sang Sang, Chow Tai Fook, TSE SUI LUEN, D-GOLD...

According to the many brand names listed above, the characteristics of brand naming can be observed by classification:

- It shows a rational, power, safe, stable, precise, fast and advanced pursuit of electrical products, such as Kelon, Galanz, Gree, Geely, Philips, HP and Asus.

- It reveals the breath of Chinese culture and uses the unique Chinese language, such as Tongrentang, Wong Lo Kat, Yuanjilin, Ronghua, Goubuli, Minxin, Taotaoju and other traditional Chinese brands.

- It names the brand after the person's name such as Fotile, Boss, Master Kong, Li Ning, TSE SUI LUEN, Disney and KFC.

- It expresses the functional characteristics of the product, such as Red Bull, Pocari Sweat, Kinder, Snickers, Weijixian and Cup Noodles. 
- It expresses the attributes of the product, such as Coca-Cola, Pepsi, D-GOLD, Dove, Sands, Xtep, etc.

Research and analysis of brand names can help designers quickly grasp the direction and tone of the design.

\section{THE BRAND LOGO DESIGN CONCEPT}

The brand logo is the visual manifestation of the brand's core concept. It appears in the form of graphics, text, or a combination of graphics and text on all brandrelated products. It can distinguish industry competition and enable consumers to identify products and services.

There are three forms of brand logo design: graphics, text, and the combination of graphics and text.

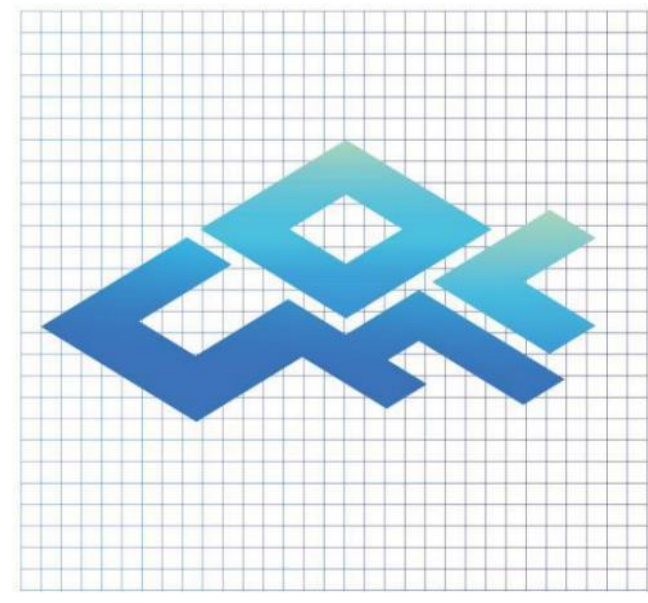

Fig. 1. HAIJI logo design — Diao Yongliang.

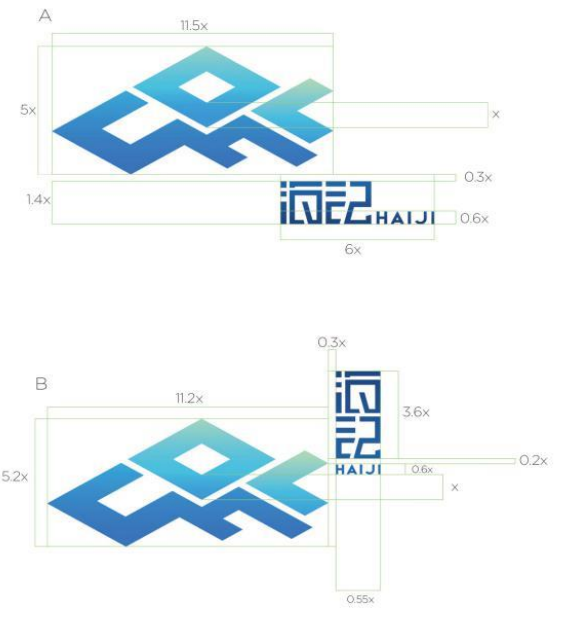

Fig. 2. HAIJI standard agency design — Diao Yongliang.

Choosing graphics as the expression form of brand logos has the advantage that graphics are easy to popularize and spread between different nationalities and cultures. Especially in the context of the Internet era today, the spread of graphic logos is faster and the audiences are wider. However, if the logo only has graphics, it is not convenient for people to communicate the correct brand information. Therefore, in addition to the logo graphics, standard fonts must be added in combination with them. The so-called standard font is the brand name. Chinese brands are mainly in the form of Chinese, supplemented by English. The standard fonts of brands need professional design by designers. Generally, ready-made commercial fonts are not used in order to improve brand recognition. The logo and standard font can be combined or used separately. The principle of design is to consider the issue of uniformity. In order to meet different typesetting needs, the logo and standard fonts can be combined in various types. As shown in "Fig. 1" and "Fig. 2", the logo design of the brand "HAIJI" and the signature design of the standard font reflect the above viewpoint. "HAIJI" is a brand that sells dried seafood. It uses the abstract graphics of sea fish as a logo, and is specially designed with Chinese and English brand names to meet different usage needs.
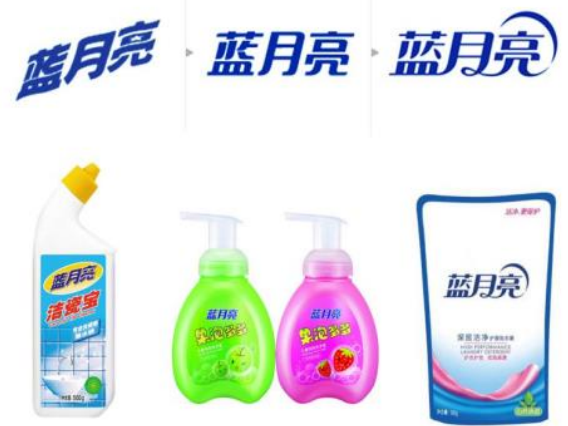

Fig. 3. Evolution of Blue Moon brand logo design http://www.bluemoon.com.cn/.

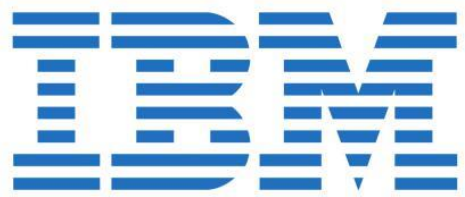

Fig. 4. Logo of International Business Machines Corporation https://www.ibm.com/cn-zh?lnk=m.

Selecting the text design of the brand name as the brand's logo is the trend of the current logo development. Modern logo designs are becoming more and more simplified, especially those with high recognition and a broad mass base. In order to meet the current pursuit of "new", major brands will choose specific opportunities and combine marketing activities 
to put forth new ideas and enhance and expand brand awareness. The Blue Moon brand in "Fig. 3" can be taken as an example. As a Chinese laundry detergent leader, the evolution and development of the Blue Moon brand logo can be called a history of development. It has witnessed the development and growth of the brand and also represents the step by step awakening of the brand awareness of Chinese companies. Brand logo design of Chinese characters is generally based on the whole brand name. While Latin characters, used in most countries in the world, its brand logo design of their characters has its own custom. Generally, the first letter of the brand's English name is used as the brand's logo design. The purpose is to use the first letter of the English name to help people remember its full name, so when choosing the first letter of the English as a sign, it is necessary to pay attention to the order of the letters. If you use the first

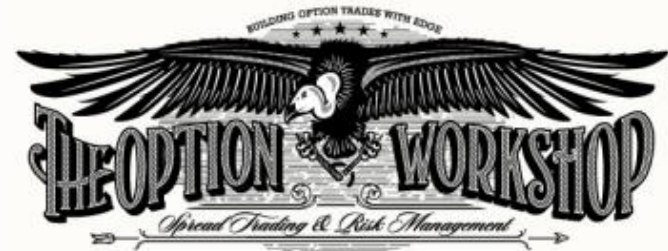

Fig. 5. Retro logo design — http://www.sj33.cn/article/bzsj/201704/47295.html.

\section{THE PRACTICAL RESEARCH OF BRAND LOGO DESIGN}

\section{A. Graphic logo design}

On the same subject matter, the expression form of graphics can be ever-changing. Graphic logo design seems difficult to start. In fact, the reason is that the design method is not mastered. The logo design of a letter as a logo design, you also need to design the brand name as a standard font design to supplement its brand information. The English name of International Business Machines Corporation is referred to as IBM, and "Fig. 4" is its brand logo.

The combination of graphics and text as the expression form of the logo will usually directly choose the combination of the brand name and the graphics. This type of logo doesn't require additional standard font design, but the biggest difference from the previous two forms is that its graphics and text can't be used separately, and from head to toe is a complete whole, that is, there is no so-called different signature design. This type of logo contains a large amount of content and information, and is generally used to express its brand meaning and traditional culturerelated, retro and nostalgic logo designs. ("Fig. 5")

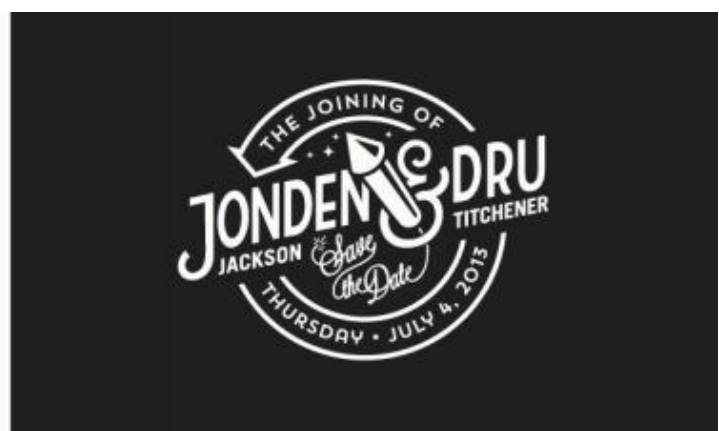

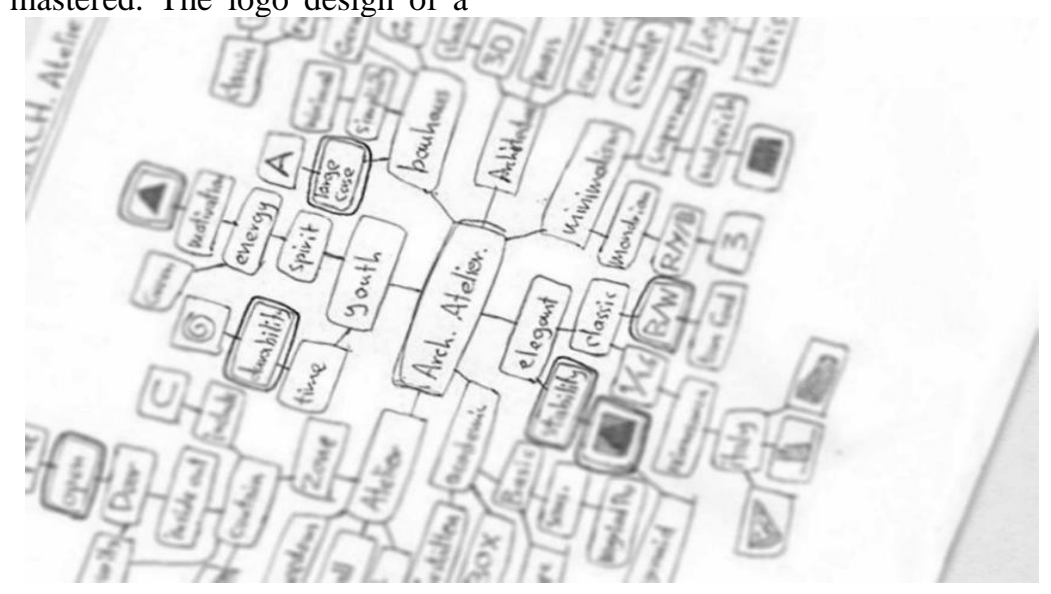

Fig. 6. Logo mind map of ARCH ATELIER - https://archatelier.net/.

brand should be the highest visual representation of the brand concept and behavior, so the logo design itself is not in terms of graphics, but it is about digging into the relevant concepts and behavioral connotations of related brands, refining them into text formulas, converting them into graphic formulas, using the wisdom of designers to look for commonality in graphics and finally completing the logo design. 
Since the author has done related design research on the brand before and has a certain understanding of the brand's content. In the design concept stage, the author needs to quickly complete a brainstorm in a limited time to refine the text formula of the logo design. The method is as follows. First, the author wrote the name of the brand in the center of the paper, deduced it in layers around the core concept and behavior characteristics of the brand, used simple words (words rather than sentences), and listed the brand's mind map,

\section{ARCH ATELIER \\ + BUILDING}

\section{A A}

Fig. 7. Logo formula of ARCH ATELIER - https://archatelier.net/

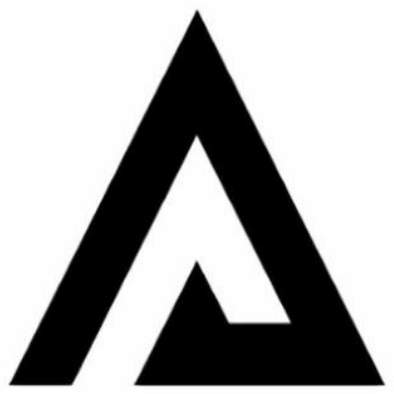

Fig. 8. Logo design of ARCH ATELIER - https://archatelier.net/.

There are two parts that need to be emphasized here What kind of graphics to choose into the formula and as shown in "Fig. 6". Then the author selected two to three most representative words among the many words, listed the text formula as shown in "Fig. 7", and then according to the text formula and selected the appropriate figure to correspond to the words in the formula with one figure corresponding to one word in order to list a new graphic formula. And the brand logo is designed through the innovative combination of graphics and graphics, as shown in "Fig. 7" and "Fig. $8 "$.

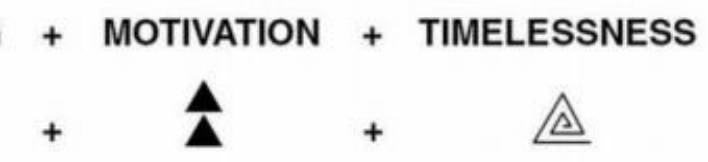

the innovative combination of graphics and graphics are the most difficult part of the entire logo design.

For the same word, there are various expression forms of graphics. "Fig. 9" is a fruit brand that can be delivered to your door. Its name is "Xinshengxian". The formula obtained from the mind map is "orange" + "bamboo dragonfly", which respectively convey the two core concepts and service characteristics of the brand, namely, fresh fruit and the fruit fast delivery service. The basic principle of the combination of graphics and graphics is that the two can be fully integrated and can see each other. Finally, the combination of the two graphics results in a new and creative graphic - a fresh fruit brand logo that can be delivered directly to your door. Although the orange and the bamboo dragonfly are combined into a new image, the meaning of the components can be quickly interpreted from it.

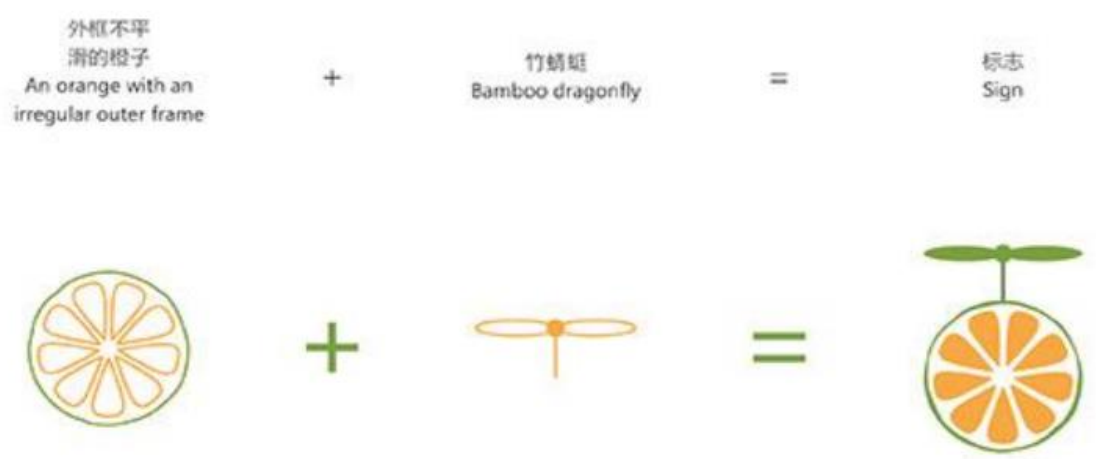

Fig. 9. Logo design of Xinshengxian — Zhong Yuemiao.

"Fig. 10" is an organic food brand. With the purpose of "green health and environmental protection", it mainly sells pollution-free, safe and high-quality nutritional foods using the green logo. Through the brand's mind map, it filtered the text formula of "shopping cart" and "carrot" as the brand logo, and the 
graphic formula of the graphic of "shopping cart" and "carrot" as the logo. The shopping cart expresses the brand's characteristics, while the cute carrot graphic expresses the characteristics of the supermarket's sales of organic food. Combining the two creative designs,
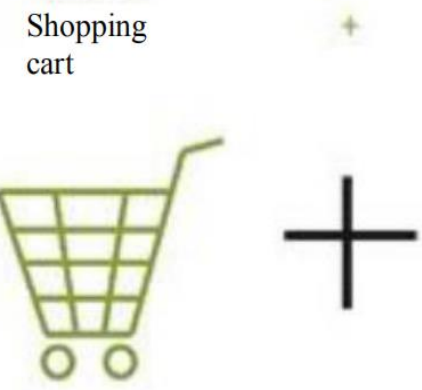

Fig. 10. Logo design of organic food supermarket — Lin Shaoping.

In the design of this part, the most common problem encountered is that there is no real combination between graphics and graphics, but they are "put" together by different typesetting. Such a combination seems extremely simple and rigid. The most appealing part of the graphic logo is the fun of displaying graphic logos in the design - the ability to subtly combine two different graphics, find out the similarities between the two, create new graphics and see each other's existence from it. It should also be noted that when enumerating text formulas, it is best not to use too many words. Of course, this is not a mandatory requirement. There are also many logo design formulas with five or six words in the market. They can also design excellent logos. Without doubt, this depends on whether the design has deep control. The more vocabulary, the more difficult the entire logo is full of design sense. Proper use of styling and colors makes people feel fresh, healthy and welcoming, and is in line with the brand's business philosophy, which is impressive.
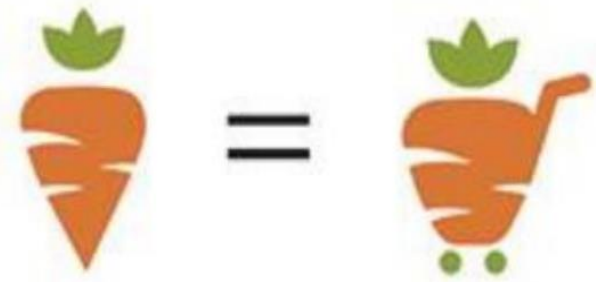

the design is. For a junior designer, if one of his logos wants to express too much content, it is often easy to express nothing and become "neither fish nor fowl". "Fig. 11" below is the logo design of the bread brand. The text formulas of the logo are "bread", "smile" and "handwork", which respectively represent the core concepts and behaviors of the bread brand's product type, attentive service and handmade products features. The text formula is converted into the corresponding graphic formula, and then the creative design is combined based on the three graphics. The completed logo design is a brand new graphic symbol. You can see the meaning represented by the three original graphics. The overall look is concise, natural and reasonable, making it very easy to remember this very friendly and delicious bread brand logo design.

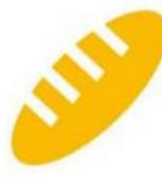

Bread

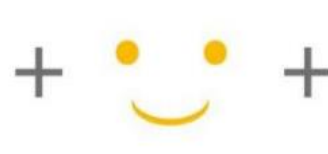

Smile

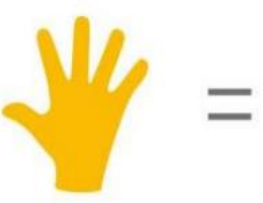

Handwork

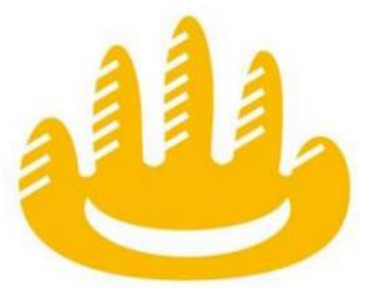

Fig. 11. Logo design of bread brand - Cai Jingyi.

\section{B. Logo design combining graphics and text}

In the logo of a combination of graphics and text, the text that appears in it is generally the brand's Chinese or English name, or a combination of Chinese and English. Since Chinese and English are two different system fonts, they are also different in design.

1) The combination design of graphics and Chinese fonts: Everyone knows that Chinese characters are hieroglyphs and pictorial characters. As more and more Chinese characters are created, the simple pictographic

method can no longer meet the needs of Chinese characters. Scholar Xu Shen of Han Dynasty summarized six Chinese character making methods in "Shuo Wen Jie Zi", which are referred to as "Liushu" (the six categories of Chinese characters), including pictographs, understanding, echoism, self-explanatory characters, concentration and borrowing.

After studying the six types of word-making methods summarized by Xu Shen, no one seems to be irrelevant to the pictographs. If the expression form of the logo is to choose the combination of graphics and 
text, it is possible to study whether the text itself has a pictographic part, and then use graphics to re-display it. This is a logo design based on the pictograph characteristics. As shown in "Fig. 12", the tea brand is called "YUNCHA". The entire logo design is both modern and very traditional. Since tea is a traditional product in China which has a history of thousands of years, its design orientation is "traditional modern design", which can reveal the cultural connotation of its brand and satisfy the hobby of young consumers. The logo design of the brand did not choose the simplified

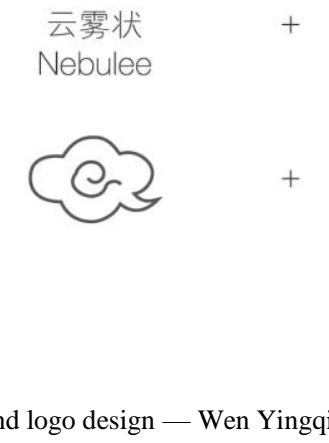

Fig. 12. YUNCHA brand logo design — Wen Yingqi.

"Fig. 13" is a brand logo design called Baiyou, which uses the initials of its brand name "百" to combine with a shopping cart. The two cleverly seek the common points of graphics and Chinese characters and combine them together. This is a typical use of the pictograph characteristics of Chinese characters for logo design. It should be noted that this method is more suitable for the number of characters between one and word "云" (cloud), but the complex font "雲". Obviously, the word "雲" is more in line with the brand's cultural characteristics and more recognizable. Therefore, the logo design focus should be on the word "雲". The word "云" in the "雲" has been replaced by a graphic design with a traditional Chinese auspicious cloud. The overall lines are thinner, appearing delicate, fashionable and young. The green standard color is in line with the attributes of tea products, while also conveying healthy and natural product features.

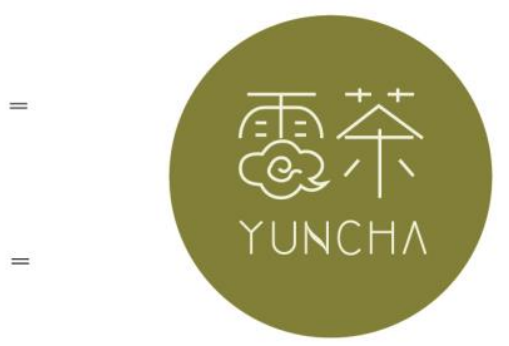

two characters. Because the logo design requirements are for the convenience of people to remember, if there are three or four characters in the brand logo and pictograms are added, the entire logo will become more complicated and even difficult to read. When encountering a brand logo with a large number of words, a unified stroke design can convey information more quickly.

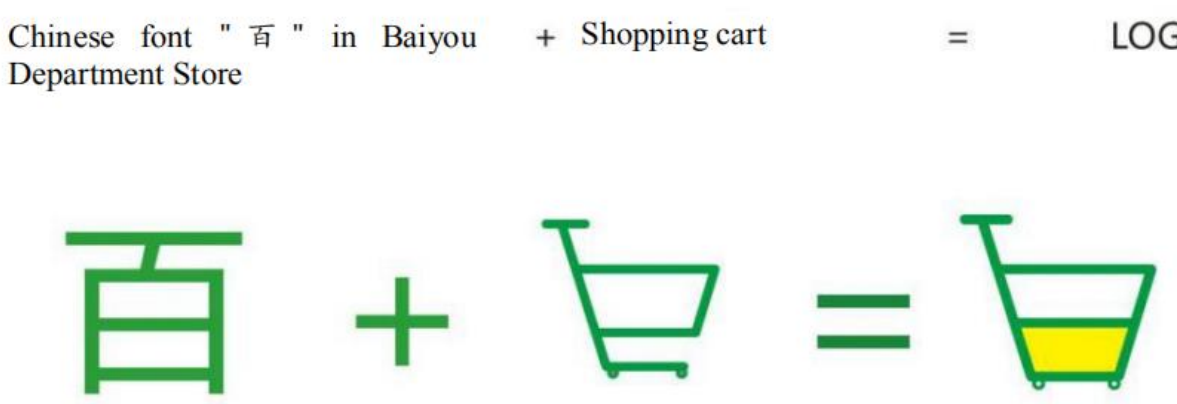

Fig. 13. Brand logo design of Baiyou Department Store — Dai Wenfeng.

2) The combined design of graphics and English fonts: In the combination of graphics and English, the brand English name is part of the logo, and the choice of letters appears more flexible. It can be the first letter of the English word or the full English name. When choosing letters for logo design, it is necessary to pay attention to the order of the letters, and you can't reverse the order of the first words in English. For example, the brand name is composed of three English words, and it is obviously wrong to extract the first letter of the second English word as a logo. Choosing the first letter of the English as the design content of the logo is to expect that the first letter will make people 
remember the name of the brand. It doesn't make any sense if the letters are randomly extracted.

Although today's English alphabets have no pictographic features and they are purely abstract visual symbols, through the designer's design, it can be given a pictographic character again. The "Fig. 14" shows the logo design of the sports brand Run. Its logo is based on the initial letter R of the brand name Run. Although R's image has nothing to do with athletes, the designer uses anthropomorphic design techniques to make the dynamic combination of $\mathrm{R}$ and athletes' running, which is very vivid and consistent with the meaning of the brand name Run.
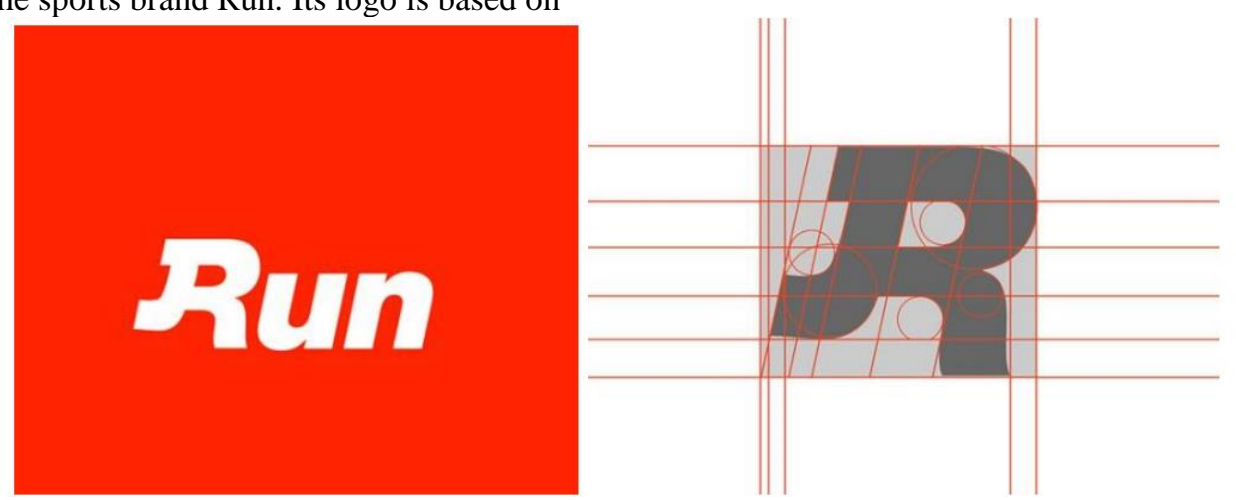

Fig. 14. Logo design for sports brand Run — http://www.th7.cn/Design/vi/201502/443805.shtml.

"Fig. 15" is a baby brand logo. The English name is Baby world. It uses the first letter of the English letter B to represent the brand name, uses the feeding-bottle to represent the baby, uses the blue to represent cleanliness and safety, treats the letter B as an image and looks for the similarities between the letter B and the feeding-bottle. Since there are two hollowed-out parts in the letter B, and the feeding-bottle also has two parts of the nipple and bottle body, the two can be well combined together. In the final formed logo, there are both letter B and feeding-bottle, which are cleverly matched. Because it is a baby brand, the lines of the entire logo are relatively round and cute, and the color blue conveys a safe and healthy message. Compared with the previous Run case, the design of Run is through the combination of the $\mathrm{R}$ letter and the running image, while the design of Baby is mainly the combination of $\mathrm{B}$ and the feeding-bottle. The design methods of the two are almost the same, both of which are looking for the commonality between the two.
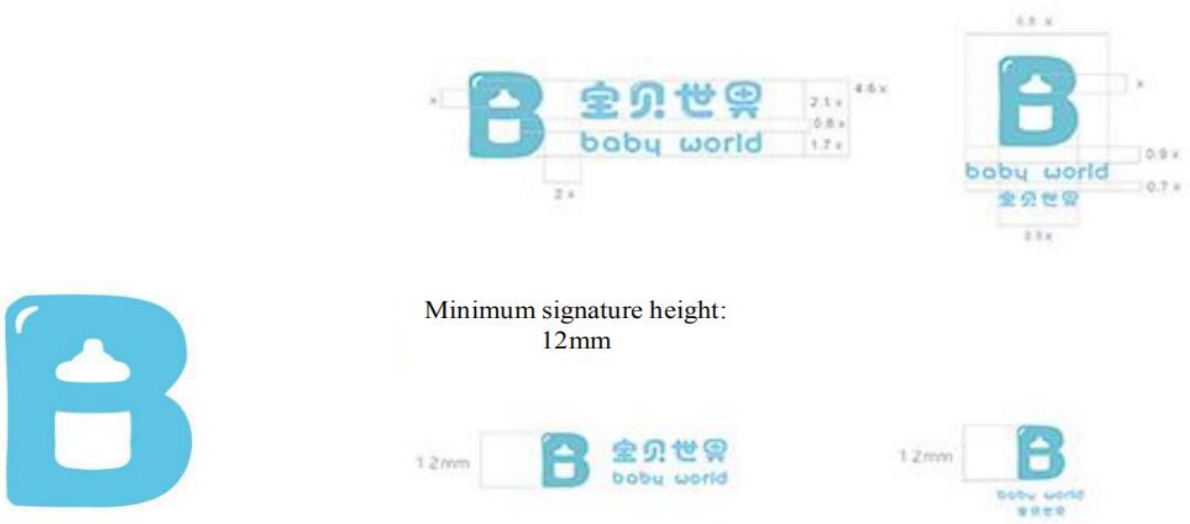

Fig. 15. Baby world brand logo design — Lin Qiwen.

The combination of graphics and characters can use the pictographic features of Chinese characters and graphics, or the combination of initials and graphics in English. In addition, the more common form is the combination of graphics and brand names. The brand name can be Chinese, English, or Chinese and English. As shown in "Fig. 16", this kind of logo design expresses more content, showing a retro and nostalgic style. The combination of finding the commonality of graphics and words described above is difficult to 
implement on such a logo. The logo combination form of "Fig. 16" is more like a "typesetting". The combination of graphics and text is relatively low. It is more of a combination of graphics, text and typography to form a new design. This kind of logo design has a strong overall sense. The graphics and the brand name can't be separated. It is a complete logo as a whole.

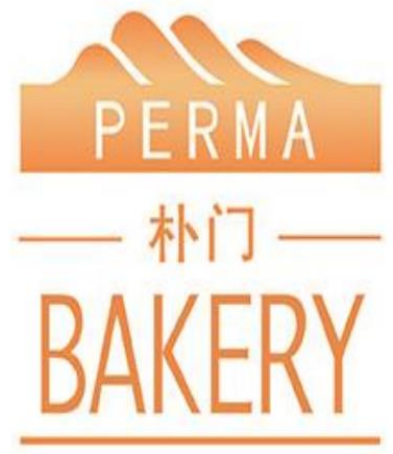

Fig. 16. PERMA bread brand logo design — Ma Mantong.

\section{Text logo design}

"Fig. 17" is the towel brand "SHUMEIKE", whose logo is the full name of the brand, a combination of three Chinese characters with lots of strokes. The text formula of its logo design is SHUMEIKE+ healthy + natural. To express "healthy" and "natural" through the font design of SHUMEIKE, it mainly uses two "leaves" instead of "口". The overall use of green expresses "health" and "natural" brand connotation. This is a typical case. The logo seems to use a combination of graphics and text, but it is completely different from the graphic and text combination case described earlier. It uses the full name of the brand as the logo, and pays more attention to the overall sense and unity of the text strokes. The appearance of the "leaves" graphic did not depart from the original structure of the font, but only served as a finishing touch.

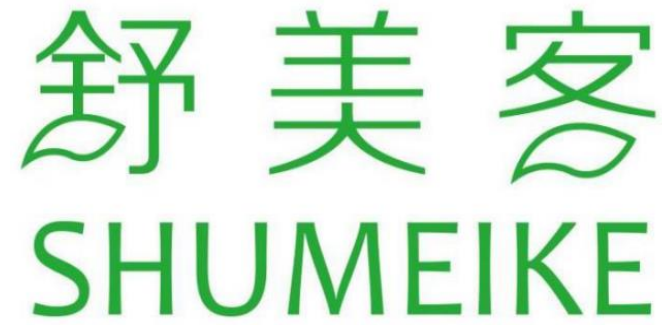

Fig. 17. SHUMEIKE brand logo design — Sun Jinxuan.

Another common Chinese font logo design can't find any shadow of graphics in Chinese. It pays attention to the design of font structure, body decoration, line thickness and colors. It focuses on showing the design aesthetics of the font design itself, and the meaning expressed is more implicit and introverted. The understanding of the brand's connotation is more dependent on the design style displayed by the logo design and the interpretation of the text content.

As shown in "Fig. 18", Guiyuan Food Container is a traditional brand of wooden food containers. Its font design method is slightly bold. It uses cuts and joinedup writing to remove some extra strokes. The shape, thickness, rotation angle, and color of the strokes are uniform. Although it is a modern typeface design, it also shows a rustic feel, which is consistent with its brand connotation.
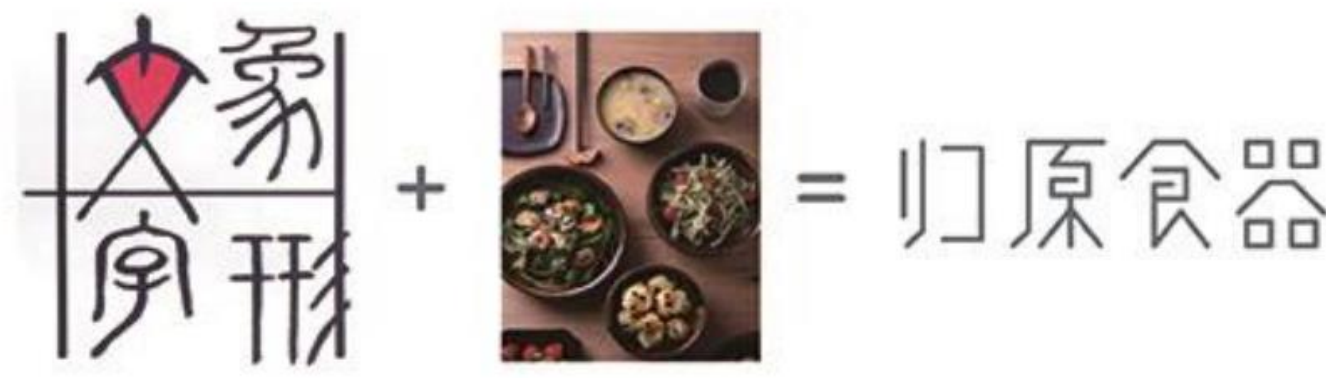

Fig. 18. Brand logo design of Guiyuan Food Container — Zheng Yongcan.

\section{CONCLUSION}

Brand logo design is based on design research. Correctly grasping the design direction and using design methods in design determines the success of logo design.
Based on the design survey, the designer grasps the design direction by listing the mind map. The design method is to extract the mind map, formulate the formula and then carry out the creative logo design of graphics, text or a combination of text and graphics. This is a scientific design process. Each step is a layer of deduction and each step is interlocking. They are all 
constrained by the brand's core philosophy and service characteristics, and are finally displayed in the form of logo design.

\section{References}

[1] Hou Liping. Logo Design [M]. Beijing: Communication University of China Press, 2010. (in Chinese)

[2] (US) Al Ries, Laura Ries. 22 Laws of Brand [M]. Beijing: Machinery Industry Press, 2013. (in Chinese)

[3] Kenya Hara. Design within Design [M]. Shandong: Shandong People's Publishing House, 2010. (in Chinese)

[4] (US) Al Ries, Laura Ries. Origin of Brand [M]. Beijing: Machinery Industry Press, 2013. (in Chinese)

[5] Xu Shi, Method of Brand Design [M]. Beijing: Pose \& Telecom Press Co., Ltd., 2018. (in Chinese)

[6] (Sweden) Cecilia Lindqvist, Chinese Character Kingdom [M]. Li Zhiyi, trans. Beijing: SDX Joint Publishing Company, 2008. (in Chinese)

[7] (German) Wolfgang Chaefer, J.P. Kuehlwein, Rethinking Prestige Branding $[\mathrm{M}]$. Li Xunnan, trans. Jiangsu: Guwuxuan Publishing House, 2017. (in Chinese) 